\title{
Interview with Scott Pellicone, Vice President of Digital Publishing Business Development for Quebecor World's Magazine Business
}

\section{Scott Pellicone}

Vice President, Digital Publishing Business Development for Quebecor World's Magazine Business. He is the lead member of the team developing breakthrough digital and technological solutions for magazine publishers in both manufacturing and revenue-generation opportunities. His responsibilities include market analysis, development of technology solutions and direct sales support to facilitate customer value and generate new business. He has over 20 years of experience in the printing business and specializes in operations, technology, general and financial management. Scott holds a BBA in Finance from the George Washington University.

Keywords: premedia, magazine publishing, e-publishing, value chains, automated publishing, cost containment

Abstract Michael Moon interviews Scott Pellicone of Quebecor World Magazine Division on their transition to a digital content management strategy, as their business expands across multiple channels. Journal of Digital Asset Management (2008) 4, 42-51. doi:10.1057/dam.2008.5

Scott Pellicone VP Digital Publishing Business Development, Quebecor World Magazin Division, 150 East 42 nd Street, 11th floor, New York, NY 10017, USA Tel: +1 (212) 6965574 Fax: +1 (212) 5836589 E-mail: scott.pellicone@ quebecorworld.com
MM: Let's start off with your full name and role at Quebecor.

SP: My name is Scott Pellicone. I am the Vicepresident of Digital Publishing Business Development for the Quebecor World Magazine Division.

MM: What does the Quebecor World Magazine Division do? What's its principle business? SP: Our principle business is putting ink on paper; however, we do have a number of ancillary businesses that support our printing business, including digital publishing, premedia and logistics. These businesses all wrap up into our supply chain.

The role of the digital publishing business is to help Quebecor World (QW) move with the marketplace toward a dual platform - print and digital - reality. My role in creating this new market is really to get more on the revenue generation side of our customers' business, rather than always being associated with the cost side.

If you look at premedia and logistics, we have always concentrated on cost containment, rather than revenue generation.
MM: I'm really glad you're bringing that up. In a lot of the presentations and conversations around digital asset management (DAM), many of the people tend to drive a productivity strategy. It's either reducing cost structure or increasing asset utilization.

SP: Exactly.

MM: They very rarely ever talk about a growth strategy. That is, how do we drive increased revenues either as a function of selling more stuff to people we already know, or creating new stuff and selling it to new people?

SP: Absolutely. I've been on both sides of the business, premedia, print, business development and sales over the past 20 years. However, over the last five years, I have been, concentrating on developing and supporting the synergies between magazine and catalogue print and premedia.

Our initial value proposition was always focused on reductions in cost and cycle time, by utilizing technology solutions to manage content as well as developing efficiencies in the publishing process via workflow automation. These solutions actually helped our customers 
internalize the process, cut costs and reduced cycle times. In fact, this strategy actually allowed the publisher to improve profitability by way of cost containment. This strategy only works in the short term, as efficiencies in process eventually become incorporated into the workflow. You can only be so efficient; there comes a time when you have to increase your volume, reinvent your business and migrate across multiple channels to drive revenue.

At Quebecor World, we utilize a digital content management strategy in our customers' workflows, to help them repurpose their creative assets, manage their brand and marketing strategy more effectively to ultimately drive revenue generation. The same assets that are delivered to our printing presses can drive website development, interactive marketing, targeted and automated publishing as well as e-commerce solutions. Then we can converge across these different market verticals by using the same digital content and provide a solution which will allow a publisher to sell a product from a magazine, or driving sales by way of a catalog to a website.

MM: Scott, I want to explore two things you've touched upon. I'd like to expand upon them. One is the notion of a digital supply chain or content supply chain. From your perspective what does that mean?

Then the second thing is the kind of transformation of magazine publishers into multimedia platforms with multiple revenue channels.

Let's start with the transformation of multimedia platforms. In another conversation interview that I've conducted, one of the things that emerged as an almost startling development...

The magazine business in North America stands in sharp contrast, for example, to the magazine business in Europe or Asia. In Europe and Asia, the Post Office does not subsidize the distribution of printed material. That's why when you launch a new magazine in Europe or Asia, principally, it's a newsstand. It's distributed at a newsstand. As a function of uptake at the newsstand, you know within two or three issues whether you've got a profitable magazine or not.

Now in the US, because of the subsidization, oftentimes what it means is that magazine publishers in North America have to really launch a magazine and they don't really know until two or three years out whether they're actually going to achieve profitability, as a function of a combination of paid circs and advertising support.

That makes the North American magazine publisher to have really good sense, in terms of what's going to work before they drop the $\$ 5$ or $10 \mathrm{~m}$ across a two- or three-year development cycle. Does that correspond?

SP: Yes. That makes a lot of sense.

MM: As a function of that, one of the things that magazine publishers are beginning to do now is - instead of launching a magazine and hoping to build an audience or readership around that, they're launching micro-sites. Dedicated websites that are heavy on the social media. Heavy on the blogs and postings. Forum discussions. Heavy on the user-generated content with uploading videos and sharing and so on.

They build an audience, first. As soon as they get to a critical mass of opted-in participating subscribers to an idea, then they've pulled the trigger and launched print magazine. Harvesting a lot of the pre-existing media assets and editorial that came from the more Wild West, unstructured stuff that you got on the web. SP: Understood

MM: Explain to me how DAM, per se, or a larger digital supply chain strategy - from your perspective at Quebecor - facilitates or accelerates that kind of a business setting. SP: This is exactly what my new role at QW is. If I could just start again and recap a little bit. Digital publishing is: (1) Revenue generation for our customers. (2) Product differentiation. QW is more than just paper-print-bind. (3) Value chain management, which all wraps up into what I refer to as, "Digital logistics."

Typically the core strategy of the logistics businesses at most of the larger commercial the printers - Quad, Quebecor and RR Donnelly, Consist of co-mail and co-palletization, two very similar manufacturing solutions that target cost containment by moving mail and printed materials more efficiently.

MM: For the readers not familiar with that particular part of the industry - what is comail and co-paletization? What does that mean? SP: Basically, we take all the magazines and catalogues that print in all our plants, and send them to a consolidation facility. At the consolidation facility, these magazines and catalogs are aggregated, sorted and bundled based on the postal carrier route, and delivered 
deeper in the postal stream to take advantage of lower per piece postage rates.

Typically, there are five stops between the print plant and your mailbox.

MM: It kind of reminds me of a simplified version of internet routers.

SP: It works much the same way. Rather than going from the plant to the local post office to the regional post office to the national post office back to the regional post office near you, back to your local post office to your home, it will go from the plant to the consolidation facility to either the national or the regional one near your home. So you've saved two or three mail stops. The product gets delivered quicker, with reduced per piece postage, and actually arrives at the mailbox in better shape because there are fewer touch points.

MM: What kind of savings are you talking about, typically?

SP: The savings are significant, approximately 1020 per cent. In addition, we can also keep track of it in that we know when the individual mail pieces are processed at the post office. We can actually mine that data and let the magazine, catalogue and direct mail publishers know that "Okay, the mail is two days away from your potential client getting the magazine, catalog, or direct mail campaign in their mailbox, so they can staff up their call centers and prepare their websites." This is the conventional logistics business.

Digital logistics is a lot of the things you were talking about. It all revolves around the vision of brand management. Publishers need to look at their magazines as brands. Not just inkon-paper or printed editions. They need to have a multichannel convergence strategy, where they can utilize their micro-sites and blogs to interact with their readers. Further, publishers can use both the printed edition coupled with the digital edition to deliver customer value by way of real-time interactive content which can compete with other more interactive medias such as television and the internet. Then there is Automated publishing for the more targeted B2B type of titles or cities and regionals or colleges and universities. Shop the magazine which actually incorporates e-commerce directly in the magazine. We also provide search engine optimization, website traffic building solutions, viral marketing, social networking as well as web2print solutions. All of the above mentioned solutions roll up into this digital logistics frontend revenue generation business.
If you think about it, those assets that are coming in as images or pages need to be repurposed. You need a common filing space or repository, which would be your DAM. These solutions need to be efficient and actually drive the production process. So technologies XML, $\mathrm{XMP}$ and JDF as well as open source, cross media publishing tools need to be included in the workflow as well.

MM: When you talk about the DAM in that context, many people associate that with, "Oh, yes. A specialized database with lots of metadata to describe photos, illustrations and videos." But it sounds like you're talking about a DAM that's larger than that, that includes tagged editorial copy - text - and treats that as an asset.

SP: Yes. Absolutely.

I think the former - what you said - your images and your pages and your videos that are tagged with some basic metadata and put into a vault - that's pretty much the legacy DAM which is being migrated into the operating system.

You're not going to go out and buy an Xinet system, a Telescope system or an Artesia system just to do that. This can easily be accomplished by a number of low cost, off the shelf solutions such as Cumulus, Portfolio, Adobe Bridge or even via the operating system using features such as Spotlight on the Macintosh operating system. What I am actually referring to is an interactive database-driven piece of technology that uses XML and RSS feeds to update websites and micro-sites and documents on the fly. It needs to be completely integrated.

MM: So you're really speaking now of what we've referred to in other places in the Journal as a digital media services platform.

SP: Yes.

MM: Visioning.

SP: It depends on the market vertical that you live in. When I wear my premedia hat, I basically represented magazine, catalogue, retail, book and direct mail. Each market vertical has very specific asset management requirements. Retail and Catalog are quite similar as their assets are typically identified by SKU, and tend to have a long useful life being used and re-used across multiple print campaigns, website and direct mail efforts.

Magazine on the other hand, are quite different as their content has a very short life and tends to expire. Images are not so important to the magazine publisher as many times they have only negotiated a one-time use of a photo 
or illustration. What is really important to the publisher is their editorial content - the final pages, the PDFs that are delivered to our press rooms. Publishers want to be able to extract and basically take that content and replicate it into a more interactive format - e-publishing, digital editions, websites, emails which can actually improve on the original printed edition.

Finally, when we look at the Book publishing DAM requirements we refer to technologies such as Ingram and Libre systems which create a digital warehouse to accommodate their archives which may include thousands of front and back list titles.

MM: Front list meaning the things that are out in the bookstore, and back lists are things that are...

SP: That are no longer in print.

MM: Right.

SP: They want to be able to do two things.

Store them in a DAM, slice them and dice them so they can actually sell bits and pieces of them through their e-commerce site. They want to be able to integrate into Amazon.com and Barnesandnoble.com, and all those web-based retailers for e-commerce.

Another revenue stream for the book publisher is to convert many of their back list titles to print on demand via the digital warehouse. The user experience would be, "I want to go find this back-list title." I go to the website and I can actually order an out-of-print book. Then the files could be extracted from the DAM, sent to the printer, the printer prints a one-off, binds it and sends it to the consumer. MM: I was suggesting, Scott, that DAM has evolved from this point solution — which is a bit-bucket, vault, check-in, check-out, to more of a services platform. And by a "service platform," the ability to add new output management type devices — be they in-design servers or image servers or webcast servers or whatever. And that it really enables very accelerated workflows.

From that, it kind of evolves into a content and services platform, where you can position new formats of pre-existing content thesis digital assets — thereby unlocking the revenue streams.

You gave a nice summarization from book, catalogue, direct and magazine. Perhaps this is the time to bring forward the topic of supply chain and how you define or explain a supply chain to a fairly smart executive. And how have these supply chains evolved over time specifically incorporating things like DAM and $\mathrm{XML}$ and web services and things like that? SP: The supply chain, basically, in my world is from creative to ink-on-paper through logistics and fulfillment. It starts with the cameras click and the photographer gets the image to the publisher - the magazine publisher - the cataloguer, the retailer, and the life of the magazine or catalogue begins in the creative part of the equation.

Not so long ago, the supply chain was quite different as we have definitely been effected by a digital evolution. Typically, way back when in the old days (10 years give or take), the photographer would shoot an image on a piece of film, the file would be developed and delivered to the agency. The agency would represent the photographer and sell the image to the publisher. The film would travel from the publisher to the lithographer, where it would be separated, proofed and incorporated into a page layout. The lithographer would forward plate ready RRED Negatives to the printer, who would print and bind the job and deliver to the distribution house for delivery to the magazine wholesalers or post office.

Now things have changed. It's not as linear. There's a lot of overlap in responsibilities. There's also a lot of sharing of content, because the same content that goes to drive the magazine print edition is also creating the e-commerce edition and the micro-site.

MM: To summarize just that one point, Scott we've gone from these decoupled, physical supply chains with silos and a lot of sneakerware or physically moving stuff from one place to another to now a digital supply chain, where things tend to move more like water through a warren or a creek or something.

It flows in a lot of different places, wherever it's needed. Need being your low spot in the creek. Instead of it being really a kind of structured linear process, it tends to be much more of a fluid, almost lateral or diagonal process, where it ebbs and flows.

SP: We've gone from a straight line to a cloud. MM: Right.

That's the way I always think of it now. Guys from production - like I started out in production. Everything followed a very linear path from beginning to end. That's not the case, any more.

Also, technology has allowed the different silos, as I had mentioned. You've got your 
creative and then you've got your production and you've got your print and your distribution silos to sort of blend together. So now creative people are doing production. Production people are now doing creative. And because we've had other different technologies that drive ecommerce and that drive the distribution of information - that is,... the internet and so on and so forth.... There are different things. It's like a hub-and-spoke type of model. That asset may be used in many different channels.

Then it gets even further complicated. Publishers and agencies are now looking more toward the globalization of the industry. Certain features and functions need to be done offshore, to save on production costs.

Silhouetting and very labor-intensive tasks can be done in China and India. They're just seconds away over an internet connection, and you're able to save 40,50 or 60 per cent of your costs. MM: Scott, I've seen what you're describing. I've seen that characterized. In fact, we characterize it as the physical supply chain becomes digital. At some point in its process or transformation into an all-digital supply chain, you end up with a redistribution of work to what we call "centers of excellence."

We define centers of excellence as highly automated, autonomous business operations that have all-digital or nearly all-digital workflows. And more importantly, they invest in ongoing productivity enhancements and efficiency gains.

That gets to one of the underlying dilemmas for a lot of companies. Whether it's Quebecor or whatever. Efficiency rarely if ever has a deadline. Unless you give efficiency a deadline, there is very little moving out of your comfort zone in order to achieve it.

We've found that these centers of excellence have emerged like collateral operations or web operations or a localization operation. They do one thing brilliantly, and better than any other node in this digital supply chain.

As you were describing, in some cases, doing the color retouch or shadowing or digital cosmetics as best done in some lower-cost labor markets like China or India - that would be an example of this redistribution of work to where you get the lowest price at minimum acceptable quality. SP: If we parallel - one comment I wanted to make was.... We have experience utilizing technology in (2008) via Avon. You've probably heard it at many of the Henry Stewart symposiums. But QW was, the first vendor/ partner of Avon to share content across the web. We started with Imation Media Manager. Then we grew to Media Bank. Then we migrated to Telescope.

MM: That came out of our Orlando operation. Is that correct?

SP: Thay is correct, QW's technology solutions center is based out of Orlando, FL and they are responsible for our hosted content management business.

The DAM deployment is an excellent case study as we were able to help Avon to significantly reduce costs, while at the same time improve quality.

Historically, Avon worked in an analog workflow, where transparencies would be duplicated 28 different times and sent out to 28 different countries and separated into 28 different renditions of the original file.

The costs associated with managing this process were quite expensive. Following our deployment of a global DAM strategy, we were able to centralize the process into one or two of our premedia centers and actually separate the image only once. Further, we took a look at Avon's budget, and identified what it had cost to process each individual image in 28 different countries. We then identified what it would cost to do it very well once, and even spent a little bit more money so Avon could actually improve their quality. Finally, we then shared that asset across those 28 countries.

We saved Avon seven figures each year for the last seven or eight years, so the hosted DAM solution the model definitely does work. However, what happens as technology changes is, there's been a tremendous devaluation of asset management.

There are a number of different DAM solutions available in the marketplace today which run the gamut, from the very high end which provides enterprise content management to fortune 500 companies; to the off the shelf applications that live on your local desktops; to the content management systems that are integrated into your computers operating system. Probably, dollar-for-dollar, they're the most robust, because you're paying a couple hundred dollars and getting a lot of features and functionality. But you don't have the check-in-check-out, the versioning, renditions and the relational database (Oracle/ $\mathrm{SQL} / \mathrm{etc}$.$) .$ 
MM: You were describing this digital media operation or digital asset operation. How do you characterize it in Quebecor?

SP: It's digital publishing.

MM: So you said that initially you started off with something and then there was MediaBank and then there was the Telescope. Has that continued to evolve in terms of your technical platform?

SP: At Quebecor we have standardized on two asset management solutions, Xinet WebNative Venture and NorthPlains Telescope. Xinet solutions touch almost every customer, and have become an integral part of our value proposition.

The other solution is based on North Plains Telescope and provides our customer with both asset and content management. We typically create an enterprise model, and use a cooperative deployment strategy to share each system across a number of customer installations. MM: One of the things I've heard about the deployment down there in Orlando is that when you had a new client, you had to create a new instance of Telescope on its own server. Have we consolidated those now? Or are we still doing multiple instances of a DAM?

SP: I believe we make another instance on the database. But they all share the same [SAN]. I think that has a lot to do with the licensing fees for Oracle.

MM: We also wanted to talk a little bit here in terms of what you were doing with the Xinet platform.

SP: I love the Xinet platform. Xinet is an interesting player in the market as their solutions touch the entire production value chain from customer facing web-based tools such as WebNative and Portal, to workflow, OPI (Open Prepress Interface), content repurposing, DAM, online approvals, file delivery and archiving. We have standardized our entire premedia production workflow on these tools, and I have not come across another developer who has such a wide array of technology that fits so perfectly into our supply chain.

I'm a big proponent of it on the workflow side through the years. They were the first to run an Apple talk stack on a UNIX platform (SGI, SUN, LINUX), as well as having one of the most reliable OPI solutions on the market. MM: For those that aren't familiar with the OPI workflows how would you describe that? SP: Basically, way back when...
MM: You mean ten years ago?

SP:Yes. I'd say ten years ago when we were very limited by processor speed, disk space and bandwidth. Xinet created technology that supported OPI.

Basically, it creates a low-resolution proxy image of a high-resolution asset that lives on a file system. It allows a creative person to place it in a document. When they print this document to their PostScript printer, Xinet's FullPress application provides OPI print queues, which sit in front of the PostScript printer that actually capture the PostScript stream with the lowresolution image in it. FullPress then replaces the low resolution proxy image with the high resolution image and sends the high resolution postscript stream to the RIP.

MM: The RIP meaning the Raster Image Process of the high-resolution image type and everything.

SP: Correct.

MM: That then becomes the basis for making the plates.

SP: Correct. So typically, if you had a 40megabyte image, you'd probably place a 300k image in your page, and you would have a very, very small file to go through the wire to the RIP. Xinet would capture the tin postscript stream $(300 \mathrm{k})$ and replace the low resolution image with the high resolution image, and send the Fat postscript stream $(40 \mathrm{mb})$ to the RIP. MM: Right.

SP: It would actually alleviate a lot of transmission time across the local area network, as the operators computer is usually tied up while spooling print data to the RIP. So by incorporating the Xinet technology into the premedia equation, we become more productive as the operator can begin working on their next job, rather than watch their computer spool print data.

Nowadays, it's not really that much of a requirement because of digital switching hubs and gigabit networks. You could place the high resolution in the page and send it to the RIP rather quickly.

MM: Or send a properly distilled Acrobat PDF. SP: Exactly. You can actually generate reliable PDFx1a output directly from the layout application.

MM: Are a lot of magazines now published from PDFs? Or is Quebecor still receiving Quark and InDesign documents and then generating printing plates or film from that? 
SP: I would say it's probably about 50/50 right now. The advent of Adobe's Creative Suite. The migration of Photoshop and PageMaker to create InDesign - where you actually have some of those PhotoShop-like features built into one application. It does however required publishers to work in a high-resolution workflow.

The fact that InDesign can generate reliable and predictable output (if your setting are correct) has allowed publishers to internalize a lot of their prepress functions. I'm seeing many publishers going in-house. They're partnering with vendors to do their overflow as they have limited resources and capacity.

If they have 13 titles, maybe they'll try to do five titles in-house. They will cherry pick the ones that make sense for them and the ones that are the easiest, and require the least amount of time and effort. Then they' will outsource the ones that are more difficult and require the most skill.

MM: From a really ruthless spreadsheet, what are we talking about, in terms of a net cost difference between doing it in-house or sending it out? Is there that much of a savings?

SP: There isn't always that much of a savings. There are certain ancillary savings like time, and more control over the entire production process. But there's definitely an intersect point where it makes sense to do it in-house need where it makes sense to actually outsource it.

MM: If I understand you right, it's not so much a cost initiative, but it's a control and time-tomarket factor that argues for them to take the stuff inside.

SP: That's absolutely correct. A lot has to do with the size of the publisher, the page count and the number of titles. Based on the urgency of the title, the schedule and the deliverables to the plants, it really is a factor of how many people you need on staff.

For example, QW Premedia could have 20 people working on 50 different titles. But a publisher may need 20 different people at one time - during one week each month - to close the magazine on schedule. So then they're still paying those 20 people for the three other weeks, that they are just waiting around for pages to arrive from the creative departments. MM: That, or they hire a bunch of temps. Right? SP:Yes. But it is really difficult to get temp or freelance people on an ongoing regular basis.
MM:Yes.

SP: The same thing happens in catalogue. It is pretty much feast or famine in the catalogue business. There's not a routine schedule where every month they are publishing a catalog. Catalogs are typically published a few times a year.

MM: One of the things, Scott that has begun to really mix that up... And I'd like you to comment on this.... A lot of magazines and catalogue companies basically are publishing first to the web. As a function of really structuring their workflow, by publishing first to the web, and because they're publishing XML content or they've got an XML workflow, they then can pour the material that would normally take a week or two weeks to print. They can take that from the web and then pour it into their print production workflows.

That represents a sea change. Whereas before, it was, "We go to the magazine first and then we have the web as an afterthought." Now because the web is so immediate, you go there first and then print now is following. Do you see that happening?

SP: Absolutely. In fact, one of the things that we've done here at QW - specific to the digital publishing business — is to publish with Texterity. We felt that...

MM: Texerity is an XML database provider. Right? SP: Yes, Texterity is a best in class provider of digital editions. Texterity manages the entire electronic supply chain as they do the conversion, host the content, market the content, populate and optimize the search engines and capture the analytic data as well.

Although, the electronic edition is not a replacement for the printed version, it does provide customer value in the form of a more interactive up to date extension of the original printed version.

MM: Actually, Scott — one of the things we've found in talking to publishers and going through really their brand strategy - and therefore, a segmentation strategy.... We found that they actually have two separate, and to some degrees highly overlapping, and in some cases not... readerships of an online versus a print. There seems to be, "I only read online," group. Then there's another group that, "I only read published work." Then there's a group that reads both, or either/and.

That creates an interesting brand strategy, and an advertising sponsorship. Because you're 
attracting different readers to different properties online or print.

SP:Yes. I would agree with that. I think the younger audiences will opt more into reading the publication on their mobile device or online. Also, their viewing patterns will be quite different than say their parents or grand parents.

Everyone's viewing patterns are different. Maybe someone in our generation that commutes will read a magazine on the train. A younger generation may be reading the magazine in front of the computer or in front of the television set. Then an even younger generation may be reading it on their mobile device.

I think the point that I am trying to make is that there should be a very logical balance as to the content that comes in the printed edition and the content that comes in the electronic edition. They should supplement one another. One should work for the other. It's almost how the internet is not a business, but it's a great facilitator for a brick-and-mortar business.

Service industries on the internet have a very difficult time generating revenue while retailers have been quite successful selling hard goods via ecommerce. I think there are lots of synergies between the printed edition and the electronic edition.

For example, if you're a monthly magazine, your content basically expires after one week. Additional news breaking content can be supplemented through a digital edition or via the publishers website. Then you can tie the two together.

The other part is the ROI. The way that magazine publishers capture ROI through the printed book isn't very good. The electronic edition is an excellent facilitator to capture ROI for your advertisers, because you can track eyeballs. Who looked at the book, when they looked at it, how much time they spent on a page, how many pages they viewed, where they came from and where they went.

MM: That gets to another key point, Scott, in the larger framework of the value chain. The value chain not only moves goods and services from points of raw materials and/or creation to ultimate consumption and disposal. But it also generates additional flows of information.

Flows of information like "Who did what?" kind of activity information. There's also transaction information, in terms of who bought what, at what price and at what time of day. All that kind of stuff.
There's also this data stream that is, "Who are you and what are you interested in?" Part of an overall digital supply chain strategy really emphasizes what we could call a business process or a business intelligence data stream.

So you're getting into that in terms of how magazines unlock additional value from their core assets as a function of providing better intelligence back to their advertisers.

SP: Absolutely.

MM: How does Quebecor participate in creating or enhancing that feedback loop?

SP: That's a great question.

MM: Either now or on the road back? SP: Our vision is to basically to continue to build this digital logistics business that will basically encompass everything that we spoke about. The data mining and the interactive marketing. The web-to-print. The social networking. The micro-sites and all that.

In the meantime, these things cannot be developed overnight. So we look for key bestin-class vendor/partners to assist us, and integrate them into our value chain. It's not a brokerage. It's not where we broker a deal. It's all about a strategic alliance whereby both companies partner to deliver value to the customer.

Our value is the convergence or the synergies created through the printing process. Where we have the files, or have helped to create these files. Further, the DAM and the content management component really helps us serve up and integrate the content into these other different value chains, including the web, direct mail and marketing, and even into television.

Eventually the internet is going to become more and more like broadcast television. You'll have different free wireless networks. The Google and MSN and Yahoo wireless networks that will capture your IP address and be able to serve up ads based on analytics. Based on traffic behaviors and things like that.

There are lots of things that are going to happen in the future. That's why we're trying to get into the e-publishing business right now. Also, the printing business is actually on a steady decline. It was based on so many different factors. People are greener, the high price of fossil fuels, postage, paper as well as alternative media channels such as TV, the internet and mobile devices.

MM: And the people under 30 prefer to read it online as opposed to in print. 
SP:Yes. Our generation is fixated on instant gratification. When we want something, we must have it immediately.

Nevertheless, we try to use our digital solutions appropriately based on the customers market vertical. For Business to Business magazines, where the information typically does not expire, the digital edition is quite valuable. For example, if you are a collector and are researching a particular 1957 Chevy, having the ability to flip through a stack of relevant magazine archives is very valuable. In fact, publisher can identify a new revenue stream by electronically publishing their archives.

MM: You just touched on it, and I think it could actually be another hour. We don't have another hour, but it could be. That's the whole thing on analytics. One of the great strengths of a robust, mature DAM as a service platform is that you've got all this asset activity and user activity data. Right? That's all in the DAM. In terms of usage journals.

SP:Yes.

MM: One of the things that we've seen that's been very powerful - especially from a service provider such as a Quebecor - is to take that activity data and to start to really mine it and organize it. Then going back to the client and saying, "Here. Let's look and see what the data says." Right?

Whether it's a process-efficiency benchmark or usage-scorecards and such. Can you speak to that a little bit in terms of the kinds of things that clients are using and the kinds of things that you see emerging as clients become more sophisticated, analytic consumers?

SP: It's all about targeting. It's all about becoming one-to-one with your audience. I think cataloguers and publishers do it very well. Trying to report on the readers' engagement with the brand, and then using that information to make educated decisions on future prospects. It's about making decisions based on fact and not intuition.

We're seeing that it increases the readers' engagement by linking the readership to advertising and content that is relevant to what they're looking for.

I think in a perfect world, the vision for the future would be something that's dynamic. Where you're looking at an electronic edition of a magazine, and as you're reading the magazine and you're looking at certain stories, the advertising will be served up based on your engagement with the content. This would be the pinnacle of target marketing.

In fact, by publishers migrating to an electronic electronic edition, we soon will be able to provide the selective serving of advertising content. The industry is aware of the need for this type of functionality, and QW is constantly for companies to invest in that can provide interactive marketing and analytic services. As I mentioned earlier, it is all about targeting. Catalogers right now use analytics to basically thin down their print run. It's about printing fewer editions but more often, and more targeted.

If they could actually use other vehicles like the internet and certain sweepstakes and clever mechanisms to identify who's interested in receiving the catalogue, they don't need to print as many. So it's part of that whole targeted response.

MM: Yes. Totally.

One of the things you just touched on is that cataloguers in particular - and magazines maybe to a lesser extent - now use analytics to basically pare down print runs. And to better segment or micro-segment aspects of their portfolio to those audiences or markets that will provide the greatest revenue for the investment. SP:Yes.

MM: So not only does this mean that we're doing shorter runs, but we're doing more analytic-driven or analysis-driven production workflows. Creative in-production workflows.

So the analytics are kind of creeping like salmon moving upstream. The analytic part is moving farther and farther upstream to, "What should we create next week?" What does the data [inaudible] process of ours in our content workflows?

So, analytics become - as opposed to a scorecard - record-keeping forensic, "What happened?" The analytics now are becoming much more integrated to the actual ideation and creation process.

SP: Okay. I would totally agree with that. Analytics basically takes over for telemarketing. MM:Yes.

SP: Telemarketing will be replaced by analytics. The catalogue is really becoming more like a direct mail piece. It's basically identifying offers to the end-reader, so they can go to the website and buy it.

MM:Yes. 
SP: Today it is very rare for a catalog reader to actually fill out the order form and mail in their order.

MM: A colleague of mine said that the catalogue is actually becoming a product placement, and a user-interface to what's on the web. What consumers real want is - they like the high-fidelity color-corrected print thing, but then they want to know what the social media around it is. What are the forum discussions and blogs around that particular thing? And are there rich media - like video or Flash animations that show various use cases and/or slice-of-life uses of this product?

SP: Exactly, in fact most people tend to perform their research on the internet to view the best possible combination of features, as well as the most competitive pricing before making a purchase.

MM: Right.

SP: If we parallel this to real life for example, let's say that you were interested in purchasing a plasma television. First you would go to Consumer Reports to see which plasma television has the best value. Then you would begin your search for the best possible price. Finally you will weigh all this information and make your purchase. The most efficient way to do this is via the internet.

MM: Oftentimes. But then have you ever tried to put a 50-inch plasma on the wall? You discover there are some very specific skill sets of hanging a 100-pound thing on the wall.

SP: Right.

MM: So I'm back to Circuit City.

SP: The other point I wanted to make was, we mentioned that the catalogue is becoming more of a direct mail piece. The magazine printed edition is becoming more of an advertisement piece for the web.

MM: Right.

SP: Almost like the newsstand is more of the product placement for the magazine.

MM: And you can go online and see it for free. SP: Exactly.

A lot of things are changing. I think the newsstands eventually are going to change and things are going to migrate more to the web.

And we are going to see a lot of portal technologies. Electronic newsstands will be pushing relevant content to your mobile device. Then there's going to have to be some sort of hooks back to the printed edition.

MM: Today, we touched upon the transformation of the magazine business into a multimedia platform, where the magazine becomes really a facilitator for driving people on the web - to where they can get a deeper and richer interaction, and where you can more specifically and more concretely quantify for your advertiser the added value of the magazine.

These digital supply chains have done a couple of things. One is really to have put an emphasis on the digital logistics piece, which you guys of course address. But it's also enabled an organic redistribution of work and workflows to lower-cost areas - specifically into centers of excellence. Highly automated low-cost, highquality operations.

As we move forward, we begin to see that analytics play a much deeper, more pervasive role in the actual business of this supply chain. Analytics about the ultimate consumer of the content, as well as the value of various segments of consumption and/or interest.

Ultimately, these analytics start to drive not just advertising rates and things like that, but these analytics start to drive the actual creation of the whole content and brand and segmentation strategies.

So it seems that in terms of a key stakeholder in the digital supply chain, it seems that analytics become a center of excellence in that DAM is a natural collection point for a whole bunch of structured data that will become increasingly useful, and strategic in an overall analytic framework. And that data mining and business intelligence and benchmarking and scorecards become really core or central to who gets invited back to play in the digital supply chain as a logistics provider.

SP: I totally agree. 